\title{
DIREITO INTERNACIONAL DO MEIO AMBIENTE: O DIREITO TRANSNACIONAL COMO SOLUÇÃO À EFETIVIDADE DAS NORMAS INTERNACIONAIS SOBRE ÁGUA DOCE
}

\section{INTERNATIONAL LAW ENVIRONMENT: THE TRANSNATIONAL LAW AS SOLUTION TO EFFECTIVENESS OF INTERNATIONAL STANDARDS ON FRESHWATER}

\author{
${ }^{1}$ Leonardo Leite Nascimento
}

\section{RESUMO}

O Direito Internacional Ambiental tem encontrado dificuldades para viabilizar à gestão conjunta e integrada das águas de Bacias de Drenagem Internacional, prevalecendo, mesmo com a crise hídrica, os interesses econômicos sobre os socioambientais. Assim, o presente trabalho teve como objetivo analisar o Direito Transnacional como solução à efetivação da gestão e tutela hidrosocial das águas compartilhadas. Nesta problemática, o método de abordagem foi o dedutivo, de procedimento científico, com uso de pesquisa bibliográfica. Os resultados demonstraram a relevância dos instrumentos de regulação transnacional, se implantados com cooperação e foco na sustentabilidade, para garantir o acesso de todos à água doce.

PALAVRAS-CHAVE: Direito Internacional Ambiental; Bacias de Drenagem Internacional; Direito Transnacional; Tutela hidrosocial das águas compartilhadas; Instrumentos de regulação transnacional

\begin{abstract}
The International Environmental Law has found it difficult to enable the joint and integrated management of drainage basins waters International, prevailing, even with the water crisis, the economic interests of social and environment. Thus, this study aimed to analyze the law Transnational as a solution to effect the management and social protection of hydro shared waters. In this issue, the approach method was deductive, scientific procedure, using literature. The results showed the importance of the instruments of transnational regulation is implemented with cooperation and focus on sustainability, to ensure universal access to fresh water.
\end{abstract}

KEY-WORDS: International Environmental Law; International Drainage Basins; Transnational Law; Social protection of hydro shared waters; Instruments for regulating transnational.

\footnotetext{
${ }^{1}$ Doutorando Programa Pós-graduação em Ciências do Ambiente e Sustentabilidade na Amazônia da Universidade Federal do Amazonas - PPG-CASA/UFAM, Amazonas, AM, (Brasil). Mestre em Direito Ambiental e pesquisador da Universidade do Estado do Amazonas - PPGDA/GEDA/UEA, Amazonas, AM, (Brasil). Oficial do Exército Brasileiro. Professor universitário - UNINORTE, Manaus, AM, (Brasil). E-mail: $\underline{\text { In0881ensino@gmail.com. }}$
} 


\section{INTRODUÇÃO}

No mundo, ao longo da história, a água doce quando apropriável com finalidades econômicas, assim considerada como recurso hídrico, sempre teve um papel geopolítico de extrema relevância, em face: da facilitação de integração e ocupação do território; da possibilidade de navegação; da limitação física de fronteiras entre países; e da disposição de condições essenciais à vida, estimulando o surgimento de cidades "ao seu redor".

Segundo Rebouças (2002, p. 16-17, grifo nosso):

O controle dos rios, como forma de dominação dos povos que habitavam os setores
hidrográficos de jusante foi praticado desde, pelo menos, 4 mil a.C. na
Mesopotâmia. [...] O controle das inundações do rio Nilo foi a base do poder da
civilização Egípcia, desde cerca de 3,4 mil anos a.C.. Nos vales dos rios Amarelo e
Indu, a utilização da água como forma de poder foi iniciada em 3 mil a.C., sendo
exercido por meio de obras de controle de enchentes e da oferta de água para
irrigação e abastecimento das populações. [...]. Para alguns, a politização e
centralizaçãao atuais do poder sobre a água teriam tido suas origens nessa época.

Os supracitados relatos históricos ilustram a importância estratégica dos recursos hídricos no âmbito das relações internacionais, precipuamente entre os Estados, em face da vinculação do poder, ao país que exerce o domínio sobre o rio, sobre a fonte de água. Contudo, com a evolução da sociedade, no caso com a urbanização das cidades e o crescimento das populações, a água doce adquiriu novos usos, outrora irrelevantes e até inexistentes.

Em face de sua crescente valoração econômica, seu uso na indústria, na geração de energia elétrica e seu emprego intenso na agricultura ocasionaram problemas ambientais graves, relacionados a gestão inadequada das fontes de água disponíveis e a consequente ameaça à disponibilidade de água doce, em quantidade e qualidade adequadas ao consumo humano. Sobre tal constatação, Petrella (2004, p. 40, grifo nosso) afirma que: “A água possibilitou a construção de cidades; sua falta e mau uso estão roubando dessas cidades a possibilidade de um futuro".

Ou seja, a escassez física e econômica da água doce, assim considerada, respectivamente, a quantidade insuficiente e a falta de recursos financeiros de um país para saciar as necessidades de sua população (RIBEIRO, 2008, p. 62), por ser recurso ambiental essencial à vida, provocada pela ação antrópica irresponsável e pela distribuição física desigual, tem afetado não somente os seres humanos, mas a manutenção de todos os ecossistemas do planeta. 
Esta realidade, segundo Caubet (2006, p. XXI) inclusive, já alterou a tradição no âmbito das relações internacionais, que antes considerava a água doce um recurso natural abundante, de boa qualidade e gratuito, relacionado ao suporte à navegação e a produção de energia elétrica, e hoje a vê como um problema, afinal o uso e a distribuição da água doce no mundo não têm suprido todas as demandas de forma adequada, ocasionando graves problemas sociais e, inclusive, já gerando conflitos, em alguns países cuja a disponibilidade é menor que $1.000 \mathrm{~m}^{3}$ (mil metros cúbicos) por habitante por ano (SHIVA, 2006, p. 17).

Desta maneira, a crise hídrica tem provocado um movimento global em prol da conscientização de todos pela utilização racional, equilibrada e adequada dos recursos hídricos disponíveis, bem como para sua conservação e distribuição as presentes e futuras gerações. Estas, respectivamente, assim consideradas, de acordo com seus conceitos jurídicos como: a coletividade de indivíduos com uma vida ativa, política e economicamente, com um perfil etário de 18 a 70 anos de idade; e compreendendo todas as pessoas vivas, menores de 18 anos, não plenamente ativas, política e economicamente (seja por restrições constitucionais ou limitações econômicas), além daquelas não nascidas ou nem mesmo concebidas (RAMOS JÚNIOR, 2012, p. 147-152).

Neste sentido, a questão da disponibilidade de água doce já tem gerado um receio global em razão do estresse hídrico, compreendido como a relação entre o estoque hídrico de um país e o volume total de água empregado por ano (RIBEIRO, 2008, p. 62-63), real em certas partes do mundo, e seu impacto direto na manutenção da vida nestes locais.

Assim, a questão chave para a discussão da água na agenda internacional, com intuito de assegurar a proteção e a qualidade da água doce, é fomentar o desenvolvimento sustentável e a estabilidade política, de modo que cada pessoa tenha acesso, seguro e a um custo aceitável, a água suficiente para levar uma vida saudável e produtiva (SILVA, 2002, p. $83)$.

Neste contexto, avulta analisar sinteticamente se o Direito Transnacional é uma solução para o alcance de efetividade das normas ambientais internacionais, em especial de tutela hidrojurídicas e sociais, para conservar as águas comuns de bacias de drenagem internacional e garantir o acesso das populações ribeirinhas a água doce essencial à vida. Neste ponto, cabe inferir o conceito da bacia de drenagem internacional, no caso, assim considerada uma zona determinada pelos limites geográficos de um sistema de águas 
interconectadas, isto é, pelas águas superficiais e subterrâneas que normalmente compartilham um terminal comum (ILA, 2004, p. 9).

Para tanto, foi utilizado o método de abordagem dedutivo, de procedimento científico, com utilização das técnicas de pesquisa bibliográfica, no intuito de se verificar a tutela jurídica da água doce pelo Direito Internacional Público e Direito Transnacional.

\section{A EMERGÊNCIA DO DIREITO INTERNACIONAL DO MEIO AMBIENTE}

O Direito Internacional do Meio Ambiente é uma realidade em nossa época. Este ramo do Direito Internacional, apesar de ainda não ser autônomo, caminha a passos largos para sua independência como ramo jurídico, haja vista sua importância e seu desenvolvimento nas últimas décadas, em especial, a partir da Declaração de Estocolmo sobre o Meio Ambiente Humano (1972). Neste sentido, convém citar o que discorre Rezek (2014, p. 244, grifo nosso):

A globalização do trato da matéria ambiental deu-se na grande Conferência das
Nações Unidas sobre o meio ambiente (Estocolmo, 1972), cujo produto foram
algumas dezenas de resoluções e recomendações, além do principal: uma Declaração
de princípios que materializava as "convições comuns" dos Estados participantes.
O ideal da conjugação harmônica do desenvolvimento com a preservação ambiental
marca presença nos princípios de Estocolmo.

Por sinal, a promoção da temática, realizada pela ONU, tem desempenhado papel fundamental no seu incremento e entrância global, com destaque para as Conferências sobre Meio Ambiente e Desenvolvimento do Rio de Janeiro (1992) e de Joanesburgo (2002) e sobre Desenvolvimento Sustentável do Rio de Janeiro (2012).

Por certo, apesar da multidisciplinaridade e transversalidade, inerente à temática ambiental, sua afinidade com assuntos de extrema importância para a vida no e do planeta, como questões sobre poluição transfronteiriça, disponibilidade hídrica, mudanças climáticas, bioética, demonstra a necessidade: de adequada regulação e tutela dos respectivos bens ambientais no âmbito jurídico; da discussão ampla e do fomento a cooperação no nível das relações internacionais; e, principalmente, da adequação e afinidade com os direitos inerentes aos seres humanos.

Afinal, no mundo globalizado atual, as fronteiras físicas delimitadoras dos Estados, estabelecidas por sua ação soberana, são a cada dia, mais e mais, relativizadas. O contexto de isolamento, preponderante em outras épocas, hoje não mais se aplica em face da necessidade 
de interação entre os países, seja no âmbito social, político, econômico, e, principalmente, na seara ambiental.

Assim infere Mazzuoli (2015, p. 1092, grifo nosso):

A proteção do meio ambiente não é matéria reservada ao domínio exclusivo da legislação doméstica dos Estados, mas é dever de toda a comunidade internacional. A proteção ambiental, abrangendo a preservação da natureza em todos os seus aspectos relativos à vida humana, tem por finalidade tutelar o meio ambiente em decorrência do direito à sadia qualidade de vida, em todos os seus desdobramentos, sendo considerado uma das vertentes dos direitos fundamentais da pessoa humana.

Tal assertiva, se justifica pela inserção de todos em uma sociedade internacional em face dos efeitos da globalização e da unicidade do meio ambiente, que não observa fronteiras entre Estados. Segundo Machado (2013, p.1227, grifo nosso):

Os Estados passaram a aceitar uma responsabilidade jurídico-ambiental no plano internacional não faz muito tempo. Neste século, através de um litígio que envolveu americanos e canadenses, caso conhecido como "Fundição Traill", é que se firmou a ideia de que os Estados são responsáveis pelos atos poluidores dos particulares, quando essa poluição passe a fronteira.

Ou seja, a ação irresponsável de um Estado ou de um particular, na jurisdição estatal, que porventura provoque um dano ambiental em seu território, acarreta efeitos não apenas em suas fronteiras, mas pode inclusive, afetar as populações dos países limítrofes e, quiçá, de todo o mundo. Como exemplo, podemos citar o caso das incertezas inerentes aos efeitos da poluição atmosférica e do aquecimento global da temperatura na superfície terrestre (efeito estufa) sobre o clima, particularmente, em face das ações antrópicas degradantes e seu relacionamento com a ocorrência de calamidades climáticas, cada vez mais usuais e devastadoras.

Além disso, por certo, o meio ambiente uma vez degradado, dificilmente conseguirá retornar ao seu status quo ante, mitigando assim, os efeitos de uma possível indenização pelo dano. Esta por si só, em face da complexidade do dano, muitas vezes, se mostra de valoração incerta e insuficiente frente a gravidade e a abrangência das consequências do mesmo, que podem incidir, inclusive, além das fronteiras do Estado causador do dano. Nesta senda, Accioly, Silva e Casella (2012, p. 909, grifo nosso) aduzem que:

A responsabilidade por danos ambientais é de difícil aplicação mesmo nos casos mais evidentes, como no caso de Chernobyl, no qual nenhum estado até hoje reclamou indenização pelos danos causados pelo acidente nuclear. Além disso, $\underline{\text { a }}$ responsabilidade só atua de forma posterior ao dano ambiental, que na maioria das vezes é irreversível. A responsabilidade por danos ambientais depende da caracterização do estado lesado (injured state), o que no âmbito do Direito Internacional nem sempre é possível, pois a lesão pode afetar não somente este ou aquele estado, individualmente, mas a comunidade internacional como um todo. 
Sendo assim, a inobservância das fronteiras pelos efeitos da degradação do ambiente promove, ainda mais, a emergência do Direito Ambiental no âmbito internacional, haja vista, seu caráter difuso e sua essência coletiva. Características que o vinculam como imprescindível e inerente aos interesses de todos os atores internacionais, em especial, dos seres humanos. Assim, assere Sirvinskas (2013, p. 918, grifo nosso):

Foi em decorrência da intensa degradação ambiental que houve a necessidade de proteger o meio ambiente em nível mundial. Como essa degradação não possui fronteiras devidamente delimitadas, resolveu-se criar, na esfera internacional, documentos com a finalidade de combater a poluição transfronteiriça. Tais documentos começaram a surgir no final do século XX com o objetivo de proteger o meio ambiente nacional mediante normas internacionais. Podemos, dessa forma, conceituar Direito Internacional do Meio Ambiente como sendo o conjunto de regras e princípios que criam obrigações e direitos de natureza ambiental para os Estados, as organizações intergovernamentais e os indivíduos.

Finalmente, a preocupação com a temática não pode se limitar as ações de alguns Estados, sejam desenvolvidos ou em desenvolvimento, sejam do Norte ou do Sul, bem como se anular frente aos interesses de alguns grupos econômicos. Rezek (2014, p. 245, grifo nosso) assere que:

As responsabilidades estatais são diferenciadas em função dos recursos de cada Estado, do seu grau de desenvolvimento, do seu patrimônio ecológico, do seu potencial poluente. Os textos do Rio de Janeiro destacam os deveres de prevenção, de precaução e de cooperação internacional, e enfatizam os direitos das gerações futuras, que não deveriam ser sacrificados em favor de um desenvolvimento a qualquer preço neste momento da história.

Pelo contrário, tal preocupação internacional deve ser ampliada com foco em mitigar os efeitos econômicos e sociais resultantes de sua desconsideração, entre os quais a pobreza, a fome e o sofrimento humano, em sua pior natureza, conforme discorre Accioly, Silva e Casella (2012, p. 894, grifo nosso):

A crescente poluição transfronteiriça e o aumento significativo no número de tragédias ambientais, a partir da década de 1960, alertou a comunidade internacional para a necessidade de tratar o meio ambiente de forma ampla e não desvinculada de questões sociais e econômicas.

Para tanto, torna-se imperioso no âmbito do Direito Internacional Público e, em especial, no do Direito Transnacional, a serem analisados a seguir, a criação de normas jurídicas internacionais uniformes, por meio de convenções, pactos, tratados ou acordos que estimulem e vinculem, cada vez mais, a cooperação de todos os países na tutela do meio ambiente, em especial, no que se refere a gestão integrada de águas compartilhadas de Bacias de Drenagem Internacional. Objetivando assim, garantir as gerações de hoje uma vida digna 
e, as do amanhã, sua existência em um planeta com disponibilidade de água, de biodiversidade e oportunidades, no mínimo, conservando as ofertas de recursos ambientais da atualidade.

\subsection{A tutela jurídica da água doce pelo Direito Internacional Público}

A organização do Estado, desde seus primórdios e em termos de integração e vida em sociedade, se relaciona a questões inerentes aos direitos sobre a água, em especial, quanto a sua importância estratégica na consolidação de cidades e seu controle como instrumento de poder. Afinal, sem água doce, potável, não há vida, sendo imprescindível as populações de todas as épocas o acesso a este recurso ambiental para uso doméstico e agrícola, bem como à realização de comércio, troca de informações e, modernamente, a indústria e a geração de energia.

Assim, a $\mathrm{H}_{2} \mathrm{O}$, esta combinação de 2 (duas) moléculas de hidrogênio com 1 (uma) de oxigênio, com o passar do tempo, adquiriu facetas múltiplas, inclusive com valor econômico, por tal considerada, recurso hídrico.

Neste sentido, segundo Rebouças (2002, p. 1, grifo nosso):

O termo água refere-se, regra geral, ao elemento natural, desvinculado de qualquer
uso ou utilização. Por sua vez, o termo recurso hídrico é a consideração da água
como bem econômico, passível de utilização com tal fim. Entretanto, deve-se
ressaltar que toda a água da Terra não é, necessariamente, um recurso hídrico, na
medida em que seu uso ou utilização nem sempre tem viabilidade econômica.

Como a água não tem o costume de respeitar as fronteiras construídas pelo homem, ao longo da história, esta tem fomentado uma interação entre várias cidades e povos de culturas distintas. Principalmente, por seu curso nos rios internacionais e além-mar, a água adquiriu papel fundamental na constituição das relações internacionais, ou seja, com seu uso preponderante na navegação foi possível a descoberta do mundo que hoje conhecemos.

$\mathrm{Na}$ questão da formação de um Direito Internacional de Águas, inicialmente de cunho iminentemente fluvial, haja vista seu uso supracitado e mais antigo, a história retrata uma evolução, relacionada a mudança de postura entre os Estados, em face do desenvolvimento dos interesses comerciais recíprocos.

Umas das primeiras teorias sobre o assunto foi a do direito de passagem inocente marítima e fluvial de Grotius, do século XVII, que não alcançou efetividade, em face da rivalidade política e do controle fiscal existente entre os países europeus da época. Outrossim, 
a liberdade de navegação contemporânea, decretada pelo Conselho Executivo Provisório da Convenção da Revolução Francesa de 1972, com fundamento jurídico no direito natural, também não foi suficiente para caracterizá-lo como de abrangência internacional, em face de seu caráter fragmentário (BREDA, 1992, p. 402 - 403).

Com efeito, a liberdade de navegação somente instou o uso dos rios à uma amplitude internacional com o Congresso de Viena de 1815. Segundo Amorim (2009, p. 138, grifo do autor):

O Ato Final do Congresso de Viena, pela primeira vez, consagrou regras jurídicas que abriram os cursos d'água internacionais a um nível multilateral. Surgia, assim, o então chamado Direito Internacional fluvial, ou o Direito Internacional dos cursos d'água internacionais, que passaria a disciplinar o tratamento jurídico dispensado aos cursos de águas doces de caráter internacional.

Sendo assim, a origem da tutela jurídica da água doce, especificamente dos recursos hídricos, dos rios e cursos d'água com relevância geopolítica e influência nas relações internacionais modernas, de forma ainda incipiente por limitar-se ao território europeu, pode ser considerada a Ata Final do Congresso de Viena de 1815. O documento teve os objetivos de organizar as fronteiras europeias alteradas pela ação de guerra napoleônica e assegurar a paz entre os países do continente. De forma, que foi definido o princípio da livre navegação dos grandes rios, haja vista a prevalência do interesse comercial internacional em utilizá-los para uma maior integração da Europa.

Cabe citar, que no continente americano, segundo Breda (1992, p. 405-406, grifo nosso):

[...] os acordos de Direito Internacional fluvial são concluídos separadamente pelos Estados limítrofes de cada rio e que os decretos sobre a matéria emanam dos respectivos Estados. Estes atos, geralmente, tornaram a navegação livre somente para os Estados ribeirinhos. Excepcionalmente, a livre navegação de rios internacionais abrangeu outros Estados. A primeira Conferência Pan-Americana, de 1889, tentou, através de uma recomendação, elaborar disposições gerais em matéria de navegação fluvial somente para os Estados ribeirinhos.

Ou seja, a preponderância do interesse comercial estimulou o uso dos rios para a navegação, de forma, que já à época, pôde-se verificar a relativização da soberania territorial estatal, justificando inclusive, a exclusão de outros usos da água julgados importantes pelos próprios Estados ribeirinhos (CAUBET, 2006, p. 5). Por certo, inicialmente, ocorreu o desenvolvimento de um direito de coexistência até o alcance, mais amplo e importante, no que tange a tutela da água doce pelo Direito Internacional, de uma cooperação entre os países. Neste sentido, Amorim (2009, p. 141, grifo nosso) infere que: 
Já no século XX, o Tratado de Versalhes, de 1919, e o Estatuto de Barcelona, de 1921, bem como a Convenção de Paris sobre o Estatuto do Danúbio, de 1921, levaram a noção liberal da navegação comercial a seu ponto culminante, ou seja, a utilização irrestrita do trânsito fluvial de cargas e passageiros por rios classificados como de interesse internacional.

A partir de então, em especial com a Convenção de Genebra de 1923, surgiu uma tendência à diversificação dos usos da água, especificamente a sua utilização para a produção de energia (BREDA, 1992, p. 412), que para Caubet (2006, p. 8, grifo nosso):

[...] não ia, na prática, constituir-se em um problema de incompatibilidade com os usos preexistentes, notadamente porque o grau de desenvolvimento econômico dos Estados europeus era praticamente idêntico e porque os diferentes usos possíveis ou existentes das águas estavam repartidos de forma homogênea entre eles. De outro lado, fora da Europa, os representantes europeus pressionavam fortemente para que os diversos países abrissem seus rios e seus portos ao comércio e à navegação de navios europeus. ${ }^{2}$

Após a $2^{\mathrm{a}}$ Guerra Mundial, a teoria dos usos múltiplos dos cursos d'água internacionais adquiriu relevância, de forma, que no início da década de 60 com o aumento de participantes nas relações internacionais, iniciou-se o embate, que perdura até os dias atuais. Da prevalência dos interesses humanos e ambientais frente o econômico, como parâmetros definidores do tratamento jurídico da água e do fomento de regras, positivadas ou não, de Direito Internacional e, mais recentemente, de Direito Transnacional sobre o tema (AMORIM, 2009, p. 148 - 149).

Afinal, as questões ambiental e hídrica adquiriram importância a partir de 1970, com a repercussão gerada pela Convenção de Ramsar (1971) sobre Proteção das Zonas Úmidas de Importância Internacional e dos Hábitats das Aves Aquáticas e, principalmente, pela Conferência das Nações Unidas sobre Meio Ambiente Humano de Estocolmo (1972). Uma vez que ambas, alicerçadas em pesquisas relatando a degradação de ecossistemas, constataram a possibilidade da finitude de recursos ambientais, como a água doce, em face do consumo e descaso humano com o meio ambiente, o que outrora era inimaginável.

De tal forma, que os atores internacionais começaram a valorar, mesmo que ainda de forma incipiente, os interesses humanos e ambientais juntamente com os econômicos. Sobre o assunto, Becker (2003, p. 275, grifo nosso) infere que:

Ontem mesmo, a água era abundante, disponível e gratuita. Hoje rarefeita, torna-se uma matéria-prima estratégica de primeiro plano, no mesmo nível do petróleo, qualificada como o "ouro azul". Por ser um meio complexo e frágil, a água constitui,

\footnotetext{
${ }^{2}$ Em consequência de reclamações da Inglaterra, da França e dos Estados Unidos, o Imperador do Brasil, pelo decreto de $1^{\circ}$ de outubro de 1867 , abre aos navios de comércio de todas as nações, a navegação do Amazonas, do São Francisco e do Tocantins (BONFILS apud BREDA, 1992, p. 406).
} 
ao mesmo tempo, recurso econômico e ecossistema, bases de múltiplos usos pela população (indústria, agricultura, navegação, produção de energia, turismo etc.). Quase todas as realizações humanas, sejam de produção ou de consumo, demandam a água, e sua substituição não é possível. A água natural se constitui, assim, em matéria-prima, produto de consumo e fator de produção, em todos os setores da economia.

O despertar para a problemática da água doce aconteceu, segundo Petrella (2004, 45, grifo nosso):

Com efeito, pelo menos desde a segunda metade da década de 70 e principalmente desde a primeira conferência mundial significativa sobre água (organizada em 1977 pelas Nações Unidas em Mar del Plata, Argentina), os líderes mundiais estão cientes dos problemas relacionadas com o acesso à água em quantidade suficiente e de qualidade adequada, e dos riscos associados às faltas crescentes e à degradação do abastecimento.

Ou seja, a questão da água doce e sua essencialidade para os ecossistemas globais adquiriu relevância com a constatação dos efeitos degradantes da ação humana irresponsável, refletida: na poluição de mananciais; no uso preponderantemente econômico; no desperdício; e, especialmente, na má gestão dos recursos hídricos disponíveis. Estes fatores somados têm acarretado problemas de disponibilidade em locais, antes com suficiência e, até mesmo, com abundância de água.

Sendo assim, a crise hídrica é realidade no mundo globalizado, no entanto, seus efeitos já têm sido percebidos, diretamente, apenas nos locais onde já preponderam cenários de escassez ou de estresse de água doce, ilustrados pela existência de restrições de acesso, quantidade e/ou qualidade da água disponível as suas populações.

Com efeito, cabe citar também a existência de outras questões prejudiciais, no caso, a distribuição desigual de recursos hídricos no mundo e o crescimento populacional. Estes quando alinhados à miséria, principalmente nos países em desenvolvimento, têm acarretado o sofrimento dos seres humanos que lá habitam, promovendo migrações para locais com água. O que configura uma verdadeira crise de governança em relação a gestão hídrica, que carece de mais eficiência gerencial para recuperação da qualidade e quantidade da água doce, bem como para o alcance de uma distribuição justa e equitativa nos países e, quiçá, no mundo.

Cabe destacar, que tal realidade tem provocado um despertamento global à possibilidade, não mais remota ou longínqua, de indisponibilidade de água doce para o consumo humano, agora não apenas limitada a países com histórico de escassez. Assim, o referido "risco socioambiental" já tem proporcionado embates disfarçados em questões políticas-culturais-econômicas e, por certo, na falha da cooperação internacional, irá 
desencadear conflitos declaradamente por água. Como infere Caubet (2006, p. 30 - 31, grifo do autor e nosso): “[...] se a expressão guerra da água for tomada especificamente como vontade de conquistar fontes, trechos de rios ou acesso às suas margens, não há dúvida de que já ocorreram e ocorrerão novas guerras".

E também Ribeiro (2008, p. 14, grifo nosso): “É sempre bom ter em mente as perdas humanas na guerra da água de Cochabamba na Bolívia, em 2000, e as tensões existentes no Oriente Médio em torno da água do rio Jordão, que configuram situações de insegurança ambiental e potencializam novas guerras por água".

Ambos autores destacam que os fatores fomentadores da crise hídrica podem, no caso da não efetividade da cooperação internacional na tutela socioambiental e da prevalência do interesse econômico-político soberano dos Estados no uso irrestrito dos mananciais atuais, instigar o surgimento de conflitos, guerras por água, como já ocorrido no passado, como solução pontual à escassez.

Por certo, convém citar que a soberania, na seara ambiental internacional, encontra respaldo no Princípio n. 2 da Declaração do Rio de Janeiro sobre Meio Ambiente e Desenvolvimento, adotada por ocasião da Conferência das Nações Unidas sobre Ambiente e Desenvolvimento Sustentável (Rio 92). No qual é reafirmado o direito soberano de cada nação explorar seus recursos naturais, de acordo com suas políticas ambientais e de desenvolvimento, assumindo somente, em contrapartida, o compromisso de não causar danos ao meio ambiente de outros Estados, em razão de atividades realizadas sob sua jurisdição ou sob seu controle (ONU, 1992).

Todavia, o cenário de crise hídrica tem estimulado a mudança de tratamento jurídico da água pelo Direito Internacional Público, considerando seu uso múltiplo e imprescindível a vida no planeta. Não mais limitando as relações entre Estados, principalmente no que se refere a utilização dos recursos hídricos fronteiriços e transfronteiriços, à navegação e à exploração de energia hidráulica.

Ou seja, com a constatação da possibilidade de finitude da água doce, os atores internacionais atentaram para a sua necessária tutela legal, visando disciplinar seu uso por meio da elaboração de várias normas internacionais, de cunho ambiental. Todavia, nestes instrumentos os Estados não têm abdicado efetivamente de premissas econômicas relacionadas ao uso soberano da água doce em seus territórios, de forma que têm tratado, 
superficialmente, das questões relacionadas ao seu acesso universal. Segundo Amorim (2009, p. 162, grifo nosso):

[...] se os tratados, convenções, declarações, metas e agendas estabelecidas para uma disciplina jurídica preservacionista das águas doces guardam consigo o mérito de demonstrarem uma mudança de atitude e de consciência por parte da sociedade internacional, também carregam consigo a mácula, ao menos no nível multilateral, de não disciplinarem as questões básicas em relação ao acesso direto da pessoa humana à agua doce tanto em qualidade quanto em quantidade.

Assim, a partir de Estocolmo (1972), entre os tratados, convenções, declarações, protocolos, diretrizes, recomendações, regras e princípios internacionais na esfera do meio ambiente, em especial da água doce, cabe destacar: a Conferência das Nações Unidas sobre Água de Mar Del Plata (1977); a Conferência Internacional sobre Água e Meio Ambiente de Dublin (1992); a Conferência das Nações Unidas para o Meio Ambiente e Desenvolvimento do Rio de Janeiro (1992); a Convenção de Regulamentação dos Usos Não-navegáveis de Cursos D'água Internacionais de Nova Iorque (1997); a Conferência Internacional da Água de Bonn (2001); a Conferência Internacional da Água de Berlim (2004); e a Conferência das Nações Unidas sobre Desenvolvimento Sustentável do Rio de Janeiro (2012).

Todavia, segundo Nascimento e Silva Filho (2014, p. 200, grifo nosso):

[...] apesar da ampliação do interesse global na tutela da natureza e consequente preservação da vida no planeta, nas últimas décadas, o Direito Ambiental Internacional substanciado formalmente em Tratados, Conferências Internacionais, Resoluções e Convenções da Organização das Nações Unidas (ONU) em vigor, em razão de seus caráteres programáticos, muitas vezes se mostrou ineficaz por ausência de mecanismos impositivos.

Por certo, como destacado por Amorim e por Becker e de acordo com a constatação de Nascimento, apesar do cenário de crise hídrica e das normativas ambientais internacionais, a dualidade recurso de valor econômico e líquido essencial a vida tem ganhado destaque. Afinal, o desequilíbrio hidrológico do planeta influenciado diretamente pelas mudanças climáticas, com regiões ainda abundantes e outras sem água, não tem impedido a prevalência do interesse desenvolvimentista e ultraliberal, que inclusive justifica a mercantilização da água doce como solução para impedir seu uso desmedido. Assim aduz Caubet (2006, p. 47 48, grifo nosso):

O consumo de água de boa qualidade, entretanto focaliza um novo aspecto de seu aproveitamento internacional. Trata-se da retirada de grandes quantidades de água, potável ou simplesmente doce, de um determinado lugar, para finalidades de exportação. [...] $\underline{\mathrm{O} \text { elemento natural escasso em um lugar e abundante em outro é um }}$ recurso. $\mathrm{O}$ dia em que alguém avalia esse recurso como algo a ser perdido e adquirido, ele se torna um bem, com estatuto eventual de mercadoria. 
Para Ribeiro (2008, p. 75, grifo nosso):

Diferente de outras questões ambientais, a do acesso à água não conseguiu mobilizar as camadas dirigentes de países para o estabelecimento de uma convenção internacional específica. Os acordos internacionais envolvendo a gestão dos recursos hídricos são numerosos, mas poucos documentos foram ratificados a ponto de entrarem em vigência. Esse cenário possibilita uma série de consequências, algumas inquietantes, como comercio internacional de água e o conflito que se gera por ela.

Frente a essa individualização dos problemas da água, cabe ressaltar o esforço da ONU em prol da afirmação, ao menos como um princípio, do acesso à água e ao saneamento como direito de todos os seres humanos, independentemente de sua nacionalidade, idade, sexo, religião, raça ou qualquer outra particularidade.

Apesar de não haver qualquer abordagem explícita sobre o direito a água na Carta Internacional de Direitos Humanos, muito menos nos Pactos subsequentes, de Direitos Sociais e Políticos e de Direitos Econômicos, Sociais e Culturais, foi estabelecido inicialmente a Observação Geral n. 15 do Comitê de Direitos Econômicos, Sociais e Culturais do Conselho Econômico e Social (ECOSOC), de 2003, reconhecendo-o como direito humano indispensável à vida digna e à realização de outros direitos, conforme substanciado em seu art. $2^{\text {o: }}$

O direito humano à água atribui a todos, água suficiente, segura, aceitável, fisicamente acessível e a um custo razoável para usos pessoal e doméstico. Uma quantidade adequada de água segura é necessária para evitar a morte por desidratação, para reduzir o risco de doenças relacionadas com a água e para fornecer água para consumir, cozinhar e realizar a higiene pessoal e doméstica (ONU, 2003, grifo e tradução nossa).

Sobre tal reconhecimento, Amorim (2009, p. 182, grifo nosso) faz questão de destacar que:

Depois da aprovação deste Comentário Geral, pela primeira vez há base jurídica porque proveniente de uma interpretação formal e oficial - para se compelir os membros da sociedade internacional, ao menos os 145 Estados-Partes do Pacto Internacional de Direitos Econômicos, Sociais e Culturais, a garantir universalmente o acesso à água potável para as necessidades elementares da vida, em quantidades $\mathrm{e}$ qualidades satisfatórias, evitando-se assim a concretização dos anseios daqueles que almejam obter lucro com a mercantilização da água.

Com efeito, convém avultar que tal posicionamento, em 2010, por meio da Resolução n. 64/292, da Assembléia Geral das Nações Unidas, foi reconhecido explicitamente, apesar da abstenção de 41 (quarenta e um) países, entre eles, Estados Unidos, Holanda, Israel, Turquia, Canadá, Japão, Suécia, entre outros (ONU, 2010a). 
Outrossim, o reconhecimento do acesso à água como direito humano fundamental também foi confirmado pela Resolução A/HRC/15/9, do Conselho de Direitos Humanos, conforme seu art. $3^{\circ}$ : “[...] o direito humano à água potável e ao saneamento é derivado do direito a um padrão de vida adequado e indissociavelmente relacionado com o direito ao mais alto padrão de saúde física e mental, bem como o direito à vida e dignidade humana" (ONU, 2010b, grifo nosso).

Assim, segundo a ONU (2014), o direito humano à água e ao saneamento deve ser garantido a todos, que devem dispor de acesso: suficiente, entre 50 (cinquenta) a 100 (cem) litros por dia, segundo a Organização Mundial de Saúde (OMS); seguro, livre de microrganismos, substâncias químicas e riscos radiológicos ameaçadores da saúde; aceitável, com cor, odor e sabor agradáveis para cada uso; fisicamente acessível, segundo a OMS, a fonte de água tem que estar dentro de 1.000 (mil) metros do horário local e a coleta não deve exceder 30 (trinta) minutos; e a um custo razoável, não excedendo $3 \%$ (três por cento) do rendimento familiar, de acordo com sugestão do Programa de Desenvolvimento das Nações Unidas (PNUD).

Paradoxalmente aos supracitados reconhecimentos, a realidade demonstra o desinteresse social dos Estados em efetivamente garantir o acesso universal de todos os seres humanos à água doce, conforme destaca Brzezinski (2012, p. 172 - 173, grifo nosso):

A análise das obrigações dos Estados de "respeitar, proteger e atingir", às quais se
refere a Observação Geral 15 do Comitê de Direitos Econômicos, Sociais e
Culturais, demonstra que não se supera o caráter individualista do suposto direito à
água. Em outras palavras: é somente o indivíduo que pode realizar o seu direito
humano à água, basta pagar por ela. [...] A Resolução da Assembleia Geral da ONU
de 28.07 .2010 por sua vez não vai além de declarar o direito humano à água, sem
propriamente definir o seu conteúdo e, mesmo assim, com oposição de grandes
atores das relações internacionais.

Ou seja, apesar do efeito vinculante das supracitadas declarações junto aos países signatários, não será o reconhecimento do direito humano à água por si só, em que pese não ser unânime e consensual no âmbito das relações internacionais, que irá resolver as questões ambientais e sociais decorrentes dos usos atuais da água. Para Ribeiro (2008, p. 14, grifo nosso): “[...] cabe promover de forma consistente e continuada práticas públicas e sociais que estimulem maior corresponsabilidade na gestão e uso da água, reduzindo o desperdício e estabelecendo mecanismos de controle quanto a sua mercantilização".

Por todo o exposto, pôde-se verificar que a problemática da água doce é de cunho socioambiental e econômico-político. Os fatos apontados demonstram que a solução não se 
encontra apenas em uma maior cooperação global e uma melhor gestão dos mananciais disponíveis para suprir as necessidades da vida no planeta.

É imperioso o envolvimento de todos, assim incluídos os atores internacionais (países, órgãos e agências internacionais e organizações não-governamentais), os grupos econômicos e a população mundial, para a realização de ações concretas. Estas alicerçadas em uma ordem jurídica internacional, eficaz, transnacional, vocacionada a garantir aspectos socioambientais e humanos, com efetividade, em prol da tutela da água doce e da vida humana em sua essência, no espaço de suas fronteiras e, também, no ambiente global, em especial, no transfronteiriço.

\subsection{O Direito Transnacional como solução para a efetividade das normas internacionais ambientais sobre água doce}

Nos tópicos anteriores deste trabalho foi analisada a evolução do Direito Internacional do Meio Ambiente, em especial pós-Estocolmo (1972), com a consolidação de princípios fundamentais e a materialização de variadas Convenções, Declarações, Tratados e Acordos entre Estados soberanos, reconhecendo-se gradativamente a importância do uso sustentável dos recursos ambientais disponíveis em suas fronteiras, sob pena dos seus esgotamentos e como medida adequada para se evitar danos ambientais transfronteiriços.

Ainda assim, segundo Habermas (2001, p. 99, grifo nosso):

Atualmente, o Estado não consegue mais dar respostas consistentes à Sociedade diante da complexidade das demandas transnacionais que se avolumam continuamente. Os problemas sociais aumentam em proporções preocupantes. Tudo leva a crer que o principal fator dessas crises cíclicas esteja localizado exatamente no próprio Estado Constitucional Moderno.

Ou seja, o Estado Moderno, "absolutamente soberano", apesar de sua relevância política interna e externa, enfrenta grandes dificuldades com os problemas transnacionais, em especial as questões ambientais. De forma, que colocar em prática os instrumentos jurídicos firmados no âmbito internacional, em virtude da preponderância usual dos interesses econômicos soberanos de cada Estado sobre a seara coletiva e metaindividual ambiental, se mostra tarefa de difícil, se não, de impossível concretude.

Afinal, as medidas vinculativas existentes no âmbito internacional se traduzem, rotineiramente, em meras tratativas e considerações gerais, cuja efetividade depende de uma 
efetiva cooperação entre os países, usualmente difícil de ser alcançada, em face da insuficiente imperatividade das normas internacionais.

De forma, que a efetividade do Direito Internacional do Meio Ambiente tem sido questionada, haja vista a difícil tarefa de lidar com temas transversais frente a dependência quanto à conveniência soberana de cada Estado assumir, ou não, o compromisso formal e material com os referidos instrumentos jurídicos internacionais, seja, respectivamente, pela ratificação e pelo cumprimento do acordado.

Nesta senda, o Direito Transnacional aparenta ser solução jurídica as relações transnacionais difusas, pertinentes as questões contemporâneas do mundo globalizado, entre as quais, as questões ambientais, em face de suas relevâncias socioeconômicas para os atores internacionais e inerentes à existência e continuidade da vida, humana e dos demais seres que habitam o planeta. Segundo Cruz e Bodnar (2009, p. 6-7, grifo nosso):

Cada espaço estatal transnacional poderia abranger vários estados e até partes
aderentes dos mesmos, com estruturas de poder cooperativo e solidário. Seus
objetivos seriam os de proporcionar condições para que a globalização esteja
submetida ao interesse da maioria das sociedades existentes, a partir de práticas de
deliberação por consenso e de participação democráticas. Uma das maiores
justificativas para a construção de espaços públicos transnacionais diz respeito à
questão vital ambiental que poderia ocupar o papel de 'tela de fundo' para a
construção tanto do Estado como do Direito Transnacionais. Ou seja, a a
estruturalização constitucionalizada, destinada a garantir os mínimos de segurança
jurídica e típica do Estado Constitucional Moderno, seria superada pela questão vital
ambiental como paradigma e que matizaria o ordenamento jurídico transnacional.

Por conseguinte, na seara ambiental tem avultado de importância a problemática contemporânea da água doce. De forma, que convém destacar que apesar de sua tutela jurídica internacional ter sofrido transformações, da liberdade de navegação e exploração econômica dos rios internacionais para a necessária gestão conjunta, integrada, equitativa e participativa das águas compartilhadas da bacia de drenagem internacional, quiçá, no âmbito do próprio Direito Internacional, não seja encontrada solução à questão do gerenciamento comum dos recursos hídricos transfronteiriços. Muito menos, à universalização do acesso à água doce, em quantidade e de qualidade própria a subsistência humana.

Afinal, quando se trata da temática hídrica, a realidade é ainda mais complexa, avultando para a alçada da transnacionalidade de interesses entre Estados, não simplesmente restrita a cooperação. Todavia, dependente de uma real integração com a definição de uma pauta axiológica comum, assim considerada, no campo da proposição, uma categoria ainda 
em experimentação que tenderia abranger valores globais, entre os quais, a questão vital ambiental (CRUZ; BODNAR, 2009, p. 10).

Para tanto, seria fundamental a constituição de espaços estatais pertinentes, como Comitês de Bacia Transfronteiriços, desta feita, estruturados democraticamente e de forma participativa entre os Estados ribeirinhos, dotados com poder de coerção, para fazer cumprir os Acordos multilaterais firmados consensualmente.

Por exemplo, esta necessidade é evidente na Amazônia, afinal o Tratado de Cooperação Amazônica (TCA), mesmo depois da criação da Organização do Tratado de Cooperação Amazônica (OTCA), não demonstra ter alcançado efetividade no que se refere a gestão hídrica conjunta da Bacia Amazônica entre seus Estados-Membros ribeirinhos. Por certo, inexiste quaisquer tratativas bi ou trilaterais, organizadora da administração das águas comuns, com a definição de um espaço comum, apesar do previsto no seu art. I, in verbis:

\begin{abstract}
As Partes Contratantes convêm em realizar esforços e ações conjuntas a fim de promover o desenvolvimento harmônico de seus respectivos territórios amazônicos, de modo a que essas ações conjuntas produzam resultados equitativos e mutuamente proveitosos, assim como para a preservação do meio ambiente e a conservação e utilização racional dos recursos naturais desses territórios. Para tal fim, trocarão informações e concertarão acordos e entendimentos operativos, assim como os instrumentos jurídicos pertinentes que permitam o cumprimento das finalidades do presente Tratado (BRASIL, 1980, grifo nosso).
\end{abstract}

Assim, como solução à pouca efetividade das normas internacionais ambientais, como o TCA, tem brotado o Direito Transnacional, buscando a harmonização de interesses dos Estados com base na integração e no estabelecimento de normas jurídicas comuns em prol da tutela socioambiental e do desenvolvimento regional sustentável.

Em especial, com relação a gestão integrada e compartilhada de recursos hídricos transfronteiriços, poderia ser estabelecido de um espaço transnacional, ultrapassando as restrições impostas pelas soberanias dos países ribeirinhos, podendo atribuir poder imperativo a Comitês de Bacia Transfronteiriços, por intermédio de um instrumento de governança, regulação e intervenção, no caso um instrumento de regulação transnacional (IRT) para fazer cumprir os objetivos comuns determinados. Assim infere Dias (2013, p. 183-184, grifo nosso):

O Direito Ambiental é um dos campos jurídicos que mais pode avançar neste campo da transnacionalidade. A crise ecológica, como característica da modernidade, é global, portanto seu tratamento necessariamente deve ser transnacional. A criação de um Direito Transnacional pode proporcionar um nível de proteção que ultrapassa a proteção que poderia advir de direitos nacionais, comunitários ou do internacional. No contexto da Amazônia, o que se propõe é a estruturação deste sistema de Direito Transnacional através de um instrumento de regulação transnacional (IRT) no 
âmbito do TCA. Com isso, o que se vislumbra é uma possibilidade de superação da insuficiência do Direito Ambiental atual na garantia da sustentabilidade da Floresta Amazônica. A ideia de integrar democracias tão jovens e de uma colonialidade ainda tão forte é desafiadora. Contudo, a necessidade desta integração, é premente, posto ser a forma mais adequada de proteção ambiental da região. Além disso, o próprio histórico latino-americano é propício à ideia de integração. [...] Diante de toda esta realidade a proposta de criação de um instrumento de regulação transnacional emerge como a tentativa de promoção de normatização transnacional, no âmbito do TCA, criada por intermédio da conjugação dos interesses comuns dos países amazônicos. Para dar exequibilidade a este Instrumento deve ocorrer de modo democrático, com etapas de ampla participação. Isso irá promover a soberania local e o enfrentamento da colonialidade, garantindo, ao mesmo tempo, a sustentabilidade ambiental amazônica e a manutenção de seus povos tradicionais, com seus modos de vida e seus conhecimentos.

Por todo o exposto, o Direito Transnacional configura-se em alternativa pertinente a problemática ambiental internacional, dependente ainda, de uma efetiva integração entre os países que disponham de uma pauta comum na seara ambiental-internacional, em todas as suas especificidades. Principalmente, no que se refere a participação e democracia de todos, entre os quais suas respectivas populações, inclusive as tradicionais, interessados no alcance do desenvolvimento sustentável comum.

\section{CONSIDERAÇÕES FINAIS}

O que se percebe, por todo o exposto, é que no âmbito internacional se caminha para o compartilhamento dos recursos hídricos disponíveis, em face do apelo de dispô-los a todos os seres humanos, de forma igualitária, para garantir vidas saudáveis com dignidade e qualidade, enquadrando o acesso à água como direito humano fundamental.

Contudo, tal posicionamento, enfrenta forte resistência proporcionada pela soberania absoluta dos países e pelas normas que tutelam a gestão hídrica na seara ambiental internacional, em especial, no Princípio n. 2 da Declaração do Rio de Janeiro sobre Meio Ambiente e Desenvolvimento, adotada por ocasião da Conferência das Nações Unidas sobre Ambiente e Desenvolvimento Sustentável (Rio 92).

O desequilíbrio hidrológico do planeta influenciado diretamente pelas mudanças climáticas, com regiões ainda abundantes e outras sem água, não tem impedido a prevalência do interesse desenvolvimentista e ultraliberal, que inclusive justifica a mercantilização da água doce como solução para impedir seu uso desmedido.

Assim, os países que têm estoques abundantes de água, apesar do cenário de crise hídrica, ainda defendem o exercício de seus direitos de exploração e não pretendem cedê-los, 
mesmo que "humanitariamente", ampliando as possibilidades de serem agravados os conflitos por água, já realidade no mundo.

Outrossim, pôde-se verificar que a problemática da água doce é de cunho socioambiental e econômico-político. Os fatos apontados demonstram que a solução não se encontra apenas em uma maior cooperação global e uma melhor gestão dos mananciais disponíveis para suprir as necessidades da vida no planeta, sendo necessário o envolvimento de todos, assim incluídos os atores internacionais (países, órgãos e agências internacionais e organizações não-governamentais), os grupos econômicos e a população mundial, para a realização de ações concretas.

Estas alicerçadas em uma ordem jurídica internacional, eficaz, transnacional, vocacionada a garantir aspectos socioambientais e humanos, com efetividade, em prol da tutela da água doce e da vida humana em sua essência, no espaço de suas fronteiras e, também, no ambiente global, em especial, no transfronteiriço

Finalmente, pelo fato das normas de Direito Internacional do Meio Ambiente, por si só, não viabilizarem à gestão conjunta e integrada das águas comuns compartilhadas nas Bacias de Drenagem Internacional, as soluções do Direito Transnacional, em especial, os instrumentos de regulação transnacional e a criação de espaços transnacionais, em uma análise sucinta, mostram-se alternativas concretas para dar efetividade à conservação dos recursos hídricos transnacionais, inclusive podendo garantir, com base na cooperação e na sustentabilidade, o acesso a água doce, direito humano fundamental, dos presentes e das gerações do amanhã.

\section{REFERÊNCIAS}

ACCIOLY, Hidelbrando; SILVA, G. E. do Nascimento; CASELLA, Paulo Borba. Manual de Direito Internacional Público. 20. Ed. São Paulo: Saraiva, 2012.

AMORIM, João Alberto Alves. Direito das águas: o regime jurídico da água doce no direito internacional e no direito brasileiro. São Paulo: Lex, 2009.

BECKER, Bertha K. Inserção da Amazônia na geopolítica da água. In: ARAGÓN, Luis E.; CLÜSENER-GODT, Miguel (Orgs.). Problemática do uso local e global da água da Amazônia. Belém: NAEA, 2003.

BRASIL. Decreto n. 85.050, de 18 de agosto de 1980. Promulga o Tratado de Cooperação Amazônica, concluído entre os Governos República da Bolívia, da República Federativa do 
Brasil, da República da Colômbia, da República do Equador, da República Cooperativa da Guiana, da República do Peru, da República do Suriname e da República da Venezuela. Planalto, Brasília, $\quad$ DF, $1980 . \quad$ Disponível em: <http://legis.senado.gov.br/legislacao/ListaPublicacoes.action?id=126133>. Acesso em: 06 jul. 2016.

BREDA, Norma. A evolução do Direito Internacional Fluvial. In: Revista de Informação Legislativa. Brasília: Senado Federal, n. 115, ano 29, p. 399-412, julho-setembro 1992. Disponível em: <http://www2.senado.leg.br/bdsf/bitstream/handle/id/176059/000472198.pdf?sequence=3>. Acesso em: 23 jun. 2016.

BRZEZINSKI, Maria Lúcia Navarro Lins. Direito internacional da água doce: fontes, regimes jurídicos e efetividade. Curitiba: Juruá, 2012.

CAUBET, Christian Guy. A água doce nas relações internacionais. Barueri, SP: Manole, 2006.

CRUZ, Paulo Márcio; BODNAR, Zenildo. A transnacionalidade e a emergência do estado e do direito transnacionais. Revista eletrônica do CEJUR. Vol. 1, n. 4, 2009. Disponível em: <http://ojs.c3sl.ufpr.br/ojs2/index.php/cejur/article/view/15054>. Acesso em: 15 set. 2016.

DIAS, Mônica Nazaré Pincanço. A proteção jurídica transnacional dos conhecimentos tradicionais dos povos amazônicos. Tese de Doutorado - Univali, Itajaí, 2013. Disponível em:

<http://www.univali.br/Lists/TrabalhosDoutorado/Attachments/42/TESE_REAJUSTADA\%2 0Monica\%202013.pdf>. Acesso em: 15 set. 2016.

HABERMAS, Jürgen. A constelação pós-nacional. Trad. de Márcio Selligmann-Silva. São Paulo: Litera Mundi, 2001.

ILA, International Law Association. The Berlin rules on water resources. Berlim, 2004. Disponível em: <http://internationalwaterlaw.org/documents/intldocs/ILA_Berlin_Rules2004.pdf $>$. Acesso em: 10 jun. 2016.

MACHADO, Paulo Affonso Leme. Direito ambiental brasileiro. 21. Ed. São Paulo: Malheiros, 2013.

MAZZUOLI, Valerio de Oliveira. Curso de direito internacional público. 9. Ed. São Paulo: Revista dos Tribunais, 2015.

NASCIMENTO, Leonardo Leite; SILVA FILHO, Erivaldo Cavalcante e. Recursos hídricos transfronteiriços: a aplicação da ação civil pública como instrumento de tutela do meio ambiente. In: Direito ambiental III - XXIII Congresso Nacional do CONPEDI, UFPB, 2014. Disponível em: <http://publicadireito.com.br/publicacao/ufpb/ficha/206.pdf>. Acesso em: 15 abr. 2016

Revista Brasileira de Direito Internacional le-SSN: 2526-0219| Curitiba | v. 2 | n. 2 | p. 233 - 253| Jul/Dez. 2016. 
ONU, Organização das Nações Unidas. Assembléia Geral. Resolução n. 64/292, 28 jul. 2010. Disponível em: <http://www.un.org/es/comun/docs/index.asp?symbol=A/RES/64/292\&referer=http://www.u n.org/waterforlifedecade/human_right_to_water.shtml\&Lang=E>. Acesso em: 24 jun. 2016. (2010a)

Conselho Econômico e Social. Comitê de direitos econômicos, sociais e culturais. Observação Geral n. 15, 20 jan. 2003. Disponível em: <http://www2.ohchr.org/english/issues/water/docs/CESCR_GC_15.pdf>. Acesso em: 24 jun. 2016.

Conselho de Direitos Humanos. Resolução n. 15/9, 30 set. 2010. Disponível em: <http://www.un.org/ga/search/view_doc.asp?symbol=A/HRC/RES/15/9>. Acesso em: 24 jun. 2016. (2010b)

Declaração do Rio de Janeiro sobre Meio Ambiente e Desenvolvimento. Rio de Janeiro, 1992. Disponível em: <http://www.onu.org.br/rio20/img/2012/01/rio92.pdf>. Acesso em: 10 jun. 2016.

. O direito humano à água e ao saneamento. UNWATER, [S.1], 29 maio 2014. Disponível em: <http://www.un.org/waterforlifedecade/human_right_to_water.shtml>. Acesso em: 24 jun. 2016.

PETRELLA, Ricardo. O manifesto da água: argumentos para um contrato mundial. Petrópolis:Vozes, 2004.

RAMOS JÚNIOR, Dempsey Pereira. Meio ambiente e conceito jurídico de futuras gerações. Curitiba: Juruá, 2012.

REBOUÇAS, Aldo da Cunha. Água Doce no Mundo e no Brasil. In: REBOUÇAS, Aldo da C.; BRAGA, Benedito; TUNDISI, José Galízia (Orgs.). Águas doces no Brasil: capital ecológico, uso e conservação. São Paulo: Escrituras Editora, 2002.

REZEK, Francisco. Direito internacional público: curso elementar. 15. Ed. São Paulo: Saraiva, 2014.

RIBEIRO, Wagner Costa. Geografia Política da Água. São Paulo: Annablume, 2008.

SHIVA, Vandana. Guerra por água: privatização, poluição e lucro. São Paulo: Radical Livros, 2006.

SILVA, Geraldo Eulálio do Nascimento e. Direito Ambiental Internacional. 2. Ed. Rio de Janeiro: Thex Editora, 2002.

SIRVINSKAS, Luís Paulo. Manual de direito ambiental. 11. Ed. São Paulo: Saraiva, 2013. 